\title{
PEDAGOGIA MONTESSORIANA: ensaio de individualização do ensino
}

\author{
Samira Saad Pulchério Lancillotti1 \\ Universidade Estadual de Mato Grosso do Sul - UEMS \\ samira.1@uol.com.br
}

\section{RESUMO:}

O presente trabalho tem por objetivo a análise da pedagogia montessoriana a partir da categoria organização do trabalho didático. Pretende-se caracterizar essa proposta pedagógica, indicar seu alcance e seus limites no esforço por superar o ensino simultâneo. Alves (2005) considera que a educação contemporânea se mantém atrelada ao ensino simultâneo, proposto por Comenius no século XVII, quando tratou de equiparar o trabalho docente ao trabalho realizado nas manufaturas. A proposta montessoriana emergiu no início do século XX, no bojo da expansão da escola burguesa; e nesse contexto educadores reformistas trataram de propor formas alternativas de organização didática que melhor correspondessem aos valores da sociedade em transformação. A pedagogia montessoriana conseguiu avançar na proposição de uma educação individualizada para o pré-escolar, com base na aplicação prática de princípios e conhecimentos advindos dos avanços das ciências que dão suporte à educação, particularmente nos da psicologia. Contudo, não se generalizou, além do que, não teve força para fecundar a organização do trabalho didático nos níveis posteriores de ensino, em que o modo simultâneo permanece vigoroso.

Palavras-chave: Pedagogia Montessoriana; Organização do Trabalho Didático; Individualização do Ensino.

\section{MONTESSORI PEDAGOGICAL METHOD: test of individualization of teaching}

\begin{abstract}
:
The objective of this work is to analyze the Montessori pedagogical method, starting from the category 'organization of didactic work'. We intend to scrutinize this pedagogical approach, indicating both its scope and its limitations with regards to overcoming simultaneous teaching. Alves (2005), considers that contemporary education remains inextricably linked to simultaneous teaching, as proposed by Comemius in the XVII Century when he equated teaching work with manufacturing work. The Montessori approach emerged in the beginnings of the XX Century, in the midst of the expansion of bourgeois schools; and in this context, reformist educators set out to propose alternative ways of didactic organization which would better correspond to the values of a changing society. The Montessori pedagogical method managed to propose an individualized education for pre-school, based on the practical application of knowledge and principles resulting from advances in those sciences which support education, particularly psychology. However, it wasn't generally accepted, and besides which it didn't have the potency to really effect the organization of didactic work in the higher levels of education, for which simultaneous teaching still remains vigorous.

Keywords: Montessori pedagogical method; Organization of didactic work; Individualization of teaching.
\end{abstract}




\section{INTRODUÇÃO}

Este trabalho traz uma breve análise da experiência de Maria Montessori, uma das mais destacadas propostas que emergiu na transição do século XIX ao XX com o intuito de reformar a educação, avançando na proposição do ensino individualizado. Para alcançar tal intento, foram estudados dois de seus trabalhos, nos quais aborda, de forma mais evidente, a organização de sua proposta. Os textos são: El método de la Pedagogia Científica, em sua terceira edição revista e ampliada, publicada em 1937, em Barcelona, pela editora Araluce; e Ideas Generales sobre mi Método, publicado em 1965, em Buenos Aires, pela editora Losada, com prólogo de Lorenzo Luzuriaga.

Para a análise, recorrer-se-á à categoria organização do trabalho didático formulada por Alves (2005), uma ferramenta teórica que lança luzes sobre as transformações históricas do trabalho docente. 2

Segundo o autor:

No plano mais genérico e abstrato, qualquer forma histórica de organização do trabalho didático envolve, sistematicamente, três aspectos: a) ela é, sempre, uma relação educativa que coloca, frente a frente, uma forma histórica de educador, de um lado, e uma forma histórica de educando (s), de outro; b) realiza-se com a mediação de recursos didáticos, envolvendo os procedimentos técnico-pedagógicos do educador, as tecnologias educacionais pertinentes e os conteúdos programados para servir ao processo de transmissão do conhecimento; c) e implica um espaço físico com características peculiares, onde ocorre. (ALVES, 2005: p. 10-11, grifos do autor).

É a partir dessa categoria que se pretende analisar a contribuição de Maria Montessori à educação escolar, caracterizar sua proposta de ensino além de indicar seu alcance e seus limites no esforço por superar o ensino simultâneo.

O ENSINO SIMULTÂNEO: forma adequada à expansão da escola moderna.

Inúmeros educadores contribuíram para o delineamento da escola moderna, que foi sendo instituída por aproximações sucessivas. No entanto, foi no século XVII, com a obra Didática Magna, que Comenius propôs, de forma mais acabada, a organização adequada à expansão escolar, por meio da instituição do modo simultâneo de ensinar, em substituição ao ensino preceptorial, de caráter individualizado, que havia marcado os períodos históricos pregressos.

Conforme o autor:

O nosso método didático exige necessariamente que todos os alunos de uma escola sejam confiados ao mesmo professor, para que os eduque e instrua com os mesmos preceitos e os forme gradualmente, desde o principio até ao fim, não admitindo nenhum na escola depois do principio das lições, nem deixando que nenhum se vá embora antes do fim. Assim se conseguirá que 
um só professor seja suficiente para uma população escolar mesmo muito numerosa, e que todos aprendam tudo, sem lacunas nem interrupções. Será necessário, portanto, que todas as escolas públicas se abram e se encerrem uma vez por ano [...] para que, em cada ano, o programa de cada classe possa ser desenvolvido e todos os alunos (a não ser que a deficiência mental de alguns o impeça), conduzidos em conjunto para a meta, sejam promovidos em conjunto à classe superior, precisamente como acontece nas tipografias, em que, tirada a primeira folha para todos os exemplares, se passa à segunda, à terceira, e assim sucessivamente. (COMÉNIO, 1996: p. 462).

O que se deu foi que o trabalhador docente deixou de ser, em definitivo, um trabalhador artesanal, para se tornar um trabalhador parcelar, que, pelo uso de instrumentos de trabalho forjados para o ensino coletivo - com destaque para os manuais didáticos -, passou a ter como objeto de trabalho a formação de um coletivo de alunos.

No esforço por ensinar tudo a todos, Comenius equiparou o trabalho docente ao trabalho realizado nas manufaturas de seu tempo, o que foi claramente indicado por Alves no livro A produção da escola pública contemporânea, no qual o autor também indicou que a forma manufatureira de organização do trabalho didático se consolidou a partir do século XIX, e preserva-se inalterada na educação escolar contemporânea.

A prática social confirma a ilação do autor de que, efetivamente, o ensino simultâneo se mantém preservado. Em todos os níveis escolares são encontrados professores diante de coletivos relativamente homogêneos de alunos - as classes -, cada uma segue um mesmo plano de estudos, os alunos acompanham as mesmas explanações, e estão sujeitos a avaliações e exigências uniformes.

No ensino simultâneo, o professor toma por referência o aluno médio, sendo instrumentos de trabalho predominantes o manual didático, a lousa, o giz e outros recursos mais recentes adequados ao ensino coletivo, como o retro-projetor e o data show. Essa organização do trabalho está perfeitamente em acordo com aquela proposta por Comenius:

[...] no exército escolar convém proceder de modo que os mais lentos se misturem com os mais velozes, os mais estúpidos com os mais sagazes, os mais duros com os mais dóceis, e sejam guiados com as mesmas regras e com os mesmos exemplos, durante todo o tempo em que têm necessidade de ser guiados (COMÉNIO, 1996: p. 178).

O ensino simultâneo foi solidificado e aprofundado ao longo do tempo, e mantémse até o presente como forma mais adequada à expansão escolar, o que se justifica, particularmente, por suas virtudes econômicas. Esse modo de ensinar atende à necessidade de universalização do ensino, imposta pela sociedade contemporânea, a um baixo custo, na medida em que se assenta na divisão e simplificação do trabalho.

A despeito disso, esteve sujeito a muitas críticas, particularmente na transição do século XIX ao XX, quando, em consonância com a grande expansão capitalista, impôs-se a universalização da educação escolar e foram sendo estruturados os sistemas nacionais de ensino.

Inúmeros educadores do período apontaram os limites do ensino simultâneo e envidaram esforços no sentido de superar esse modo generalista de ensinar, que passa ao largo das idiossincrasias do alunado, como ritmos, interesses, dificuldades e habilidades 
particulares. A demanda por uma educação que atendesse às características singulares dos alunos ganhou corpo com a consolidação da ordem burguesa, que prima pelo individualismo.

Educadores reformistas defrontaram-se com o desafio de conciliar expansão escolar com individualização do ensino e muitos se empenharam na busca de novas respostas. Nesse processo, a psicologia ganhou relevo particular como ciência que serviria de suporte para o reconhecimento e atendimento das demandas singulares do alunado. O mote psicológico, emerso desde Pestalozzi, foi ganhando corpo no curso do século XX.

Há que se dar o devido destaque ao amplo movimento da Escola Nova, por sua grande penetração na educação contemporânea, ao menos enquanto ideário.

Cambi aponta:

A característica comum e dominante dessas 'escolas novas', que tiveram difusão predominantemente na Europa ocidental e nos Estados Unidos, deve ser identificada no recurso à atividade da criança. A infância, segundo esses educadores, deve ser vista como uma idade pré-intelecutal e pré-moral, na qual os processos cognitivos se entrelaçam estreitamente com a ação e o dinamismo, não só motor, como psíquico da criança. A criança é espontaneamente ativa e necessita, portanto, ser libertada dos vínculos da educação familiar e escolar, permitindo-lhe uma livre manifestação de suas inclinações primárias. Em conseqüência desse pressuposto essencial a vida da escola deve sofrer profundas mudanças: deve ser, se possível, afastada do ambiente artificial e constritivo da cidade; a aprendizagem deve ocorrer em contato com o ambiente externo, em cuja descoberta a criança está espontaneamente interessada, e mediante atividades não exclusivamente intelectuais, mas também de manipulação, respeitando desse modo a natureza 'global' da criança, que não tende jamais a separar conhecimento e ação, atividade intelectual e atividade prática. (CAMBI, 1999: p. 514-515).

O movimento da Escola Nova baseou-se, predominantemente, nas contribuições de Rousseau, Pestalozzi e Froebel, nos avanços da psicologia e na crítica ao caráter elitista da educação tradicional. Saviani destaca que se a educação burguesa tradicional colocara o acento na formação moral do homem, a versão escolanovista o deslocou para a "formação do indivíduo egoísta independente, membro ajustado da sociedade burguesa". (1999: p.192).

Esse movimento colocou em pauta a rediscussão das finalidades e da organização do ensino, assim como, tratou de reformular os conteúdos da educação em estreita articulação com o processo de hegemonização da ordem capitalista e, também, de avançar no desenvolvimento de uma organização do ensino que lhe correspondesse. Foi marcado por incontáveis experiências que vieram de parte de renomados educadores, e de contextos os mais diversos.

“MÉTODO MONTESSORIANO": individualização no ensino do pré-escolar

Dentre as propostas que procuraram avançar na proposição de uma nova forma de organização do trabalho didático, que respondesse ao desiderato da individualização do ensino, uma das que ganhou maior destaque foi a de Maria Montessori (1870-1952), 
primeira médica a se formar na Itália - pela universidade de Roma - e por isso ser conhecida como a 'doutora'.3

Inicialmente, seu foco de atenção esteve voltado à educação de crianças com deficiência, e foi sobre essa experiência que a autora criou um método de educação adequado ao pré-escolar, que toma por bases gerais as idéias de liberdade, atividade e independência (MONTESSORI, 1965, p.15). Para Montessori, a educação consiste em "colocar o individuo em condições de forjar seu próprio caminho na vida" (ibid.: p. 95).

A proposta pedagógica de Montessori se assentou fundamentalmente em princípios científicos advindos da psicologia, sobre os quais desenvolveu nova organização didática e novos instrumentos de trabalho, buscando formas de contemplar demandas singulares dos alunos.

Conforme a autora, enquanto a ciência fez da escola um campo experimental, não trouxe à ela contribuições significativas. Isso só ocorreu no momento em que, por meio dos avanços científicos, chegou-se à definição de qual seria o ambiente mais propício ao desenvolvimento psíquico. Os resultados práticos desse entendimento permitiram simplificar o trabalho escolar e aliviar a pressão sobre alunos e professores. À luz desse entendimento, foi possível traçar " a verdadeira reforma da escola, aquela que resolve com a maior simplicidade os mais árduos problemas" (ibid.: p. 51).

$\mathrm{Na}$ terceira edição, corrigida e ampliada, do livro El Método de la Pedagogia Científica4, Montessori oferece uma introdução ao método5 de ensino que havia desenvolvido e aplicado na educação de crianças de três a seis anos de idade nas Case dei Bambini, instituídas em Milão desde o início de 1907. A autora pondera que, a despeito de ser uma experiência ainda incompleta, circunscrita à educação de crianças pequenas, o método já se constituía em um todo orgânico, podendo ser adotado com garantias de sucesso nos abrigos infantis e, ainda, no primeiro grau das escolas primárias.

Destaca que seus trabalhos foram marcados pela preocupação em diferençar educação de crianças do estudo de crianças. Essa afirmação implica uma crítica à prática corrente de seu tempo de denominar Pedagogia Científica como o estudo do desenvolvimento infantil, sem que tais estudos servissem, propriamente, à edificação de uma nova pedagogia.

A proposta educacional desenvolvida por Montessori para o pré-escolar fundava-se sobre a educação dos sentidos. Considerou que a educação dos sentidos tinha enorme importância pedagógica, e que seria a base necessária ao pleno desenvolvimento biológico do indivíduo, sobre o qual se edificaria sua adaptação social.

Ainda segundo a autora:

Nosso objeto educativo deve ser o de ajudar o desenvolvimento da infância, não o de dar-lhes cultura. Por isto, depois de haver oferecido à criança o material didático adequado para provocar o desenvolvimento dos sentidos, devemos esperar que se desenvolva a atividade de observação. (MONTESSORI, 1937: p. 199, grifo nosso).

Como se vê, a pedagogia montessoriana objetiva a ajuda ao desenvolvimento normal do indivíduo, e não a transmissão de conhecimento. Para alcançar tal intento, a autora advoga a adaptação do ambiente às necessidades e à personalidade dos alunos. Um 
ambiente onde a vigilância e os ensinamentos do adulto sejam reduzidos ao mínimo necessário. $\mathrm{O}$ ambiente deve ter móveis e objetos simples, práticos e atraentes, que se prestem plenamente à atividade infantil.

\begin{abstract}
A tarefa da educação se divide entre a mestra e o ambiente. A antiga mestra 'ensinante' foi substituída por um conjunto muito mais complexo; quer dizer, coexistem com a mestra muitos objetos (os meios de desenvolvimento) que contribuem para a educação da criança. A profunda diferença que existe entre nosso método e as chamadas 'lições de coisas' dos métodos antigos reside em que os 'objetos' não são uma ajuda para a mestra que há de explicar suas lições, ou seja, não são 'meios didáticos'. São, em contrapartida, uma ajuda para a criança que os escolhe, que se apropria deles, os utiliza e se exercita segundo suas próprias tendências e necessidades e conforme os impulsos que o objeto desperta. Desta feita, os objetos se convertem em 'agentes estimulantes de sua própria atividade'. Os objetos, não o ensino da mestra, são o principal; e, como quem os utiliza é a criança, é este o ente ativo, não a mestra. (MONTESSORI, 1937: p. 176, grifo nosso).
\end{abstract}

Vê-se como, no método montessoriano, os materiais adquirem imenso relevo, e o papel da mestra consiste em explicar seu uso. Montessori destaca a imensa dificuldade enfrentada pelas professoras que atuam nos moldes tradicionais, para adaptar-se ao seu método de ensino. Para atuar nas escolas montessorianas, era necessário que as professoras renunciassem à posição de 'ensinantes', adotando uma nova postura: a de oferecer simplesmente o apoio para que as crianças explorassem plenamente todas as possibilidades inscritas nos objetos, e fazê-lo na medida da necessidade dos alunos. Nos termos da autora:

A mestra deve conhecer muito bem o material, tê-lo sempre muito presente na memória e aprender com exatidão a técnica experimentalmente determinada de apresentar o material e tratar a criança convenientemente para guiá-la com eficácia. Isto é o essencial na preparação da mestra. Poderá estudar teoricamente alguns princípios gerais utilíssimos para orientar-se na prática, mas só com a experiência adquirirá as delicadas modalidades que variam tratando com indivíduos distintos, para não entreter mentes já desenvolvidas com materiais inferiores às capacidades individuais, provocando o fastio, e não oferecer objetos que a criança não pode apreciar ainda, esfriando assim o primeiro entusiasmo infantil. (MONTESSORI, 1937: p. 177, tradução nossa).

Segundo Montessori, quando uma criança se auto-educa e o próprio material the indica seus erros, resta à mestra observar e dirigir a atividade psíquica das crianças e o seu desenvolvimento fisiológico, tal concepção justifica sua preferência pelo termo 'diretora', em substituição ao 'professora'.

Outro aspecto de grande relevo no método montessoriano relaciona-se à ordenação do ambiente. Como foi dito, os objetos presentes nas classes são adequados à atividade infantil, apropriados ao desenvolvimento de cada fase. São atrativos, coloridos, simples, leves e, ao mesmo tempo, resistentes. De cada objeto particular, existe um único exemplar. 
Os objetos são cuidadosamente dispostos e ordenados no recinto. Cada criança faz sua própria escolha dentre aqueles disponíveis. E, após utilizá-los, segundo seus próprios interesses e seu próprio ritmo, deve limpá-lo, arrumá-lo, recolocando-o no lugar de onde o retirou, para que possa ser utilizado por outra criança. Se uma criança quiser utilizar algum objeto que esteja em uso por um colega, terá de esperar seu turno; desse modo, exercita-se, segundo a autora, a paciência e a disciplina, e elimina-se a competição entre os pares.

Montessori considera que, com seu método, conseguiu equacionar o problema da educação individual, com um mínimo de gasto e energia. Indica que, a despeito dos inúmeros esforços envidados no sentido de alcançar esse objetivo, a única resposta encontrada fora a de reduzir o número de alunos por classe, de modo a permitir que a professora estudasse cada criança individualmente, com vistas a conduzi-la segundo as tendências que pudesse identificar. Desse modo, cada mestra só poderia ter sob sua custódia um número reduzidíssimo de alunos. Nesses moldes, eram exigidas professoras especializadas, para um trabalho minucioso e fatigante.

De acordo com a autora, sob seu método, ao contrário, não há necessidade de limitar o número de alunos por classe, ou de disponibilizar uma quantidade enorme de material, e, tampouco, de recorrer a profissionais altamente preparados. Em suas classes é possível atender ao menos quarenta alunos, sem que o mestre necessite de qualquer preparação científica. O que lhe cabe é aplicar bem a arte de eliminar-se, e não obstaculizar o crescimento da criança em suas múltiplas atividades (MONTESSORI, 1965: p. 49-50).

Esse desenvolvimento é guiado pelo descobrimento e pela utilização dos períodos sensitivos, balizas psicológicas da nova educação. Oferecer à criança as atividades atinentes às necessidades de cada fase de desenvolvimento, este o problema intrínseco da nova pedagogia. Contudo, essa não é uma tarefa das mais simples, porque os conteúdos escolares, no mais das vezes, são definidos com base em critérios culturais e não psicológicos.

Com base nesse aspecto, Montessori propôs que as atividades escolares fundadas em elementos culturais fossem analisadas e decompostas nos seus vários fundamentos psicológicos e fisiológicos, de modo que, progressivamente, a criança estivesse preparada para construções mais elaboradas. A autora toma, por exemplo, o mecanismo da escrita, que pode ser trabalhado desde idade precoce e de forma indireta, a partir de exercícios sensoriais adequados para o desenvolvimento da firmeza e agilidade manual, de tal modo que a criança passe a apresentar habilidade superior no momento de aprender a escrita propriamente dita.

Montessori argumenta:

Havendo alcançado a educação nas 'Case dei Bambini' um nível tão elevado, logicamente deve transformar-se toda a organização do ensino primário. Não é momento de examinar como deverá ser esta reforma do ensino primário; o único que direi é que estaria completamente abolido o primeiro grau. A escola primaria do porvir receberá crianças como as nossas que saberão vestir-se, despir-se, lavar-se, que conhecerão as regras da correção nos modos e estarão sobejamente disciplinadas, e me atrevo a dizer que estarão disciplinadas porque foram educadas com liberdade. (MONTESSORI, 1937: p. 269). 
Ao estabelecer paralelos entre o método montessoriano e as demais experiências modernas de educação, a autora sublinha:

Até nas escolas chamadas modernas, onde se acredita oferecer educação individual, existe uma marcada diferença com as escolas Montessori. Ali existe um professor que ensina uniformemente a coletividade, conceito profundamente diferente do aluno no método Montessori, que consiste em livrar a criança do professor que ensina e substituí-lo por um ambiente onde a criança possa escolher o que é adequado a seu próprio esforço e às necessidades íntimas de sua personalidade. (MONTESSORI, 1965: p. 93).

Destaca, também, que o preceito moderno de que é necessário conhecer a criança antes de educá-la funda-se num a priori, e, em seu método, contrariamente, parte-se do princípio de que não é possível conhecer de antemão o educando, pois as atividades psíquicas profundas são latentes e só podem ser reveladas pela compenetração e pela atividade do próprio educando. Desta perspectiva, é a pedagogia que revela a psicologia, e não o oposto. (ibid.: p. 94).

Com respeito aos programas de estudo e a instrução, Montessori advoga que sejam assentados sobre a construção da independência do aluno, e, ainda, na natureza de sua personalidade. Cada aluno deve avançar quando tenha alcançado o grau de maturidade necessário às aquisições culturais. A progressão não deve fundar-se no ano escolar, mas estar logicamente ligada ao movimento intelectual de cada aluno e tomando por guia a idade e grau de desenvolvimento de cada um.

Montessori admite que as velhas gerações devam guiar os passos das novas, mas deixando que o desenvolvimento se processe naturalmente. Para ela, o fato de o professor ocupar um papel menos ativo não equivale a dizer que deve ser eliminado. Ele assume um papel de guia dirigente e também de animador, deve ter uma personalidade entusiasta sensível e interessada nos progressos do aluno, deve ser uma pessoa inteligente e viva, com grande saber e experiência, de modo a servir de inspiração para os discípulos. (MONTESSORI, 1965: p. 106-107).

Inspiração para "ser", para sentir-se capaz de agir por si mesmo, de alcançar uma finalidade por meio de recursos e esforços próprios. Para Montessori, toda a ação progressiva que permite a apropriação das conquistas culturais só pode ser empreendida sobre a independência; e é sobre ela que deve ser edificada uma nova organização escolar. Considera que a independência é uma conquista gradual que se estabelece à medida que o indivíduo adquire novas funções, capacidades e adaptações no curso de seu desenvolvimento.

Pondera que a adolescência é a fase da vida em que surgem sentimentos sociais e se produz a necessidade de associação. Essas condições são desprezadas pela educação corrente que se limita ao uso de um material escolástico, muito distante de uma vida de relação, donde advém uma série de problemas, como a rebeldia dos alunos contra os educadores e sua repugnância à escola.

A autora advoga que é preciso entregar nas mãos do adolescente um trabalho verdadeiro, que requeira responsabilidade. Considera que o trabalho é a base que torna possível o desenvolvimento da personalidade e promove, concomitantemente, o progresso nos estudos. "Por isso proclamo a necessidade de que o adolescente se afaste da família e 
empreenda verdadeiros trabalhos [...] e comece a experimentar como se ganha a vida". (ibid.: p. 117).

Montessori argumenta que o conhecimento científico deve se desenvolver a partir da experiência social de um indivíduo independente, e que a independência econômica só se resolve na associação disciplinada de trabalho, base moral para estudos de grau superior. "Este será o maior impulso para o 'conhecimento' do presente e do passado da humanidade". (MONTESSORI, 1965: p. 119).

A despeito das considerações da autora de que seu método serviria de base segura para repensar os níveis mais avançados de ensino, isso não ocorreu e tampouco se generalizou no nível pré-escolar. Não se pode, contudo, minimizar sua expansão, pois o método montessoriano encontrou seguidores entusiastas em todos os cantos do globo; não teve força, contudo, para fecundar amplamente as práticas escolares ao longo do século $\mathrm{XX}$.

\section{CONCLUSÃO}

Em seu esforço por superar o ensino simultâneo, Montessori conseguiu avançar efetivamente na individualização do ensino, e o fez com base na simplificação do trabalho docente. Diferentemente do preceptorado, marcado por uma relação educativa de caráter individual, na qual o mestre responsabilizava-se pela educação de um, ou poucos, discípulos. A autora, com fulcro nos avanços das ciências que dão suporte à educação particularmente nos da psicologia e em suas aplicações práticas -, propôs uma forma de organização do trabalho didático em que seria possível a individualização do ensino, mesmo em se tratando do atendimento de um grande número de alunos.

A autora assegura que sua pedagogia está centrada no aluno, e esse entendimento é corroborado pela historiografia da área. Contudo, a nosso juízo, ao contrário do que se afirma, a pedagogia montessoriana se posta sobre a aplicação de avanços científico/técnicos. A exemplo do que ocorreu em outras formas de trabalho especializado, o trabalho docente foi simplificado pelo recurso a novos meios de trabalho.

Como se afirmou, o grande desafio posto à educação no século $\mathrm{XX}$ foi o de promover avanços no sentido da individualização do ensino em concomitância com a expansão escolar, sem que isso implicasse maiores investimentos econômicos em atividade improdutiva. Não prevaleceria qualquer tentativa que se opusesse à lógica do sistema.

A despeito de haver avançado na individualização do ensino, as modificações introduzidas por Montessori não permitiram a ampliação da escala de atendimento escolar, como também não se consolidaram nos níveis mais avançados de ensino. Donde se conclui que seus ensaios não tiveram potência para superar o modo simultâneo de ensinar, o qual se manteve vigoroso em todos os níveis de ensino.

$\mathrm{Na}$ educação contemporânea mantém-se o sistema de ensino com graus e programas definidos a serem alcançados pelo conjunto de alunos, o que é expressão própria de que a racionalidade técnica do trabalho - tão cara à Idade Moderna - marca também o trabalho docente. As reformas e modificações que se instauraram desde então ainda não entraram em contradição com essa organização, a despeito das vigorosas transformações materiais por que passa a sociedade presente. 


\section{REFERÊNCIAS}

ALVES, G. L. A Produção da Escola Pública Contemporânea. Campinas: Autores Associados, Campo Grande: UFMS, 2001.

O Trabalho Didático na Escola Moderna: formas históricas. Campinas:

Autores Associados, 2005.

CAMBI, F. História da Pedagogia. São Paulo: Ed. UNESP, 1999.

COMÉNIO, J. A. Didáctica Magna. 4. ed. Lisboa: Fundação Calouste Gulbenkian, 1996.

EBY, F. História da Educação Moderna. 2.ed. Porto Alegre: Globo, 1976.

LARROYO, F. História Geral da Pedagogia. 2. ed. II tomo. São Paulo: Mestre Jou, 1974.

MONTESSORI, M. EI Método de la Pedagogia Científica. Barcelona: Araluce, 1937.

Ideas generales sobre mi método. 3. ed. Buenos Aires: Losada, 1965.

SAVIANI, D. A Nova Lei da Educação: LDB trajetória, limites e perspectivas. 5.ed.

Campinas: Autores Associados, 1999.

\footnotetext{
${ }^{1}$ Doutora em História e Filosofia da Educação-UNICAMP, professora da Universidade Estadual de Mato Grosso do Sul/UEMS/Unidade de Campo Grande.
}

2 Na obra "O Trabalho Didático na Escola Moderna: formas históricas", Alves considera: "[...] a organização do trabalho didático é uma categoria subordinada, desde o momento em que é produzida no campo da educação. Mas sua importância é inquestionável para o estudo histórico das relações educativas, no âmbito das instituições sociais nas quais se realiza. A organização do trabalho didático constitui-se, conceitualmente, nos limites de outras categorias mais centrais, tais como trabalho e organização técnica do trabalho, e as implica. Daí, também, a sua riqueza, pois, ao embutir categorias centrais importantes para a revelação das relações sociais, permite que a discussão da educação e da escola desvele as características mais profundas que as permeiam. Portanto, ao estudioso que celebra o trabalho como uma categoria fundamental para o entendimento das relações sociais, só pode se afigurar desejável e promissora a iniciativa de se investigar a educação e a escola com base no trabalho didático.” (2005: p. 10).

${ }^{3}$ Outras iniciativas pedagógicas avançaram na proposição de uma educação individualizada, dentre as quais Larroyo (1974) salienta: a auto-educação de Madame A. Deschamps; a Escola Serena de Lombardo Radice; o Método Mackinder; o Plano Howard e o Plano Dalton. Contudo, o trabalho de Maria Montessori foi o primeiro e mais difundido ensaio nesse sentido.

${ }^{4}$ Publicado pela primeira vez em 1912, em inglês.

${ }^{5}$ A autora se refere à sua proposta pedagógica como Método Montessoriano; portanto, a manutenção dessa terminologia ao longo do texto.

Artigo recebido em: 20/03/2010

Aprovado para publicação em: 12/06/2010

Revista HISTEDBR On-line, Campinas, número especial, p. 164-173, mai.2010 - ISSN: 1676-2584 173 